\title{
Review
}

\section{Punishment, participatory democracy and the jury}

\author{
Albert W. Dzur, \\ Oxford University Press, Oxford, 2012, ix+221 pp., ISBN 978-0199874095
}

Contemporary Political Theory (2014) 13, e4-e6. doi:10.1057/cpt.2013.21

Punishment, Participatory Democracy and the Jury develops a normative theory of the jury as central to the successful sustenance of democratic governance. Given the empirical status of juries in our legal system, it might seem like a fool's errand to look there for sparks of civic engagement. Less than 5 per cent of all cases go to jury trial in the United States. Few citizens have the opportunity to do more than receive a summons in the mail and call in every night to be told that she will not be needed. Nonetheless, Dzur's study of the place of juries in democracy is cautiously optimistic as it argues for the role of the jury in democratizing our otherwise self-referential and hyper-rationalized system of justice seeking.

Dzur begins his study of juries, democracy and punishment with the observation that while as a culture we are fascinated with all things law-related, that fascination seems to hold only as long as those law-related dramas are mediated through culture and virtual devices, movies, books and video games. He puzzles about the fact that jury duty, the single opportunity we have as laypersons and as citizens to be directly involved with the drama of the law, is typically thought to be a burden. Yet he goes on to note that once involved, jurors tend to take up the task they are given in an engaged and deliberative fashion. 'Lay participation in criminal justice is needed because it brings otherwise attenuated people into contact with suffering human beings, draws attention to the ways laws and police and institutional structures prolong that suffering, and makes possible, though does not guarantee, greater awareness among participants of their own responsibility for laws and policies and structures that treat people humanely' (p. 14). This observation frames Dzur's critical intervention in literature on democracy and punishment.

The criminal justice system is the primary focus of Dzur's book. It is there that the violence of the state is brought to bear; it is in this context that we should be most urgently concerned about just outcomes. He challenges scholarship on the penal system to be wary of relying on expertise and professionalism as a means by which to counter the system of mass incarceration. What he characterizes as the "penal populism' argument suggests that uninformed, alienated citizens, driven by suspicion about the capacities of the state to defend and protect their interests, have 
underwritten harsh penal policies and practices that have driven the incarceration rate in the United States to excessive heights. Dzur advises caution about the conclusion often reached in this scholarship, that citizens should be kept at arm's length from the penal system. He identifies the jury, restorative justice practices and deliberative polling as evidence that it is not 'the public' per se that is the problem, but the terms on which they are brought into or excluded from the process of justice seeking. Barker's (2009) comparative study of incarceration policies in Washington and California also offers evidence that populist and democratic approaches to criminal justice are not themselves the problem; it is whether citizens are deliberatively engaged in policymaking that makes the difference in outcomes. Her work explains the significant difference between the high incarceration rates in California, driven by voters and politicians, and the lower rates in Washington, driven by deliberative assemblies and engaged citizens. In other words, countering Whitman's (2003) thesis that our criminal justice system suffers from too much democracy, Barker and Dzur suggest that it suffers from too thin a version of democratic engagement. Dzur's democratic theory of the 'load-bearing' jury counters the endgame invited by Whitman's thesis of more reliance on professionalism and bureaucracy as buffers between the public and the accused/condemned. Dzur argues that we should invest faith in the deliberative processes of laypersons as the best hedge against an otherwise hyper-rationalized legal system. For Dzur, juries play an important role precisely because, unlike social movements and civic organizations, they are part of the Constitutional structure of our justice system and have a long history as a hedge against state power.

Dzur's optimism is driven in part by the established place the jury holds in our legal system and traditions. Following Alexis de Tocqueville and John Stuart Mill, he argues that the jury is a site of civic capacity building. He describes Tocqueville's theory of the jury as functioning as a Trojan Horse in reverse: 'It carries citizens into quasi-aristocratic corridors of professional legal power only to have them return to the public with enhanced appreciation for the rule of law' (p. 65). Mill emphasizes the activity of being a juror as critical to cultivating public awareness in a culture that habituates individuals to self-interest and inwardness. Tocqueville and Mill's civic schoolhouse theory of the jury does not adequately capture the more radical task Dzur argues that the jury enacts. Dzur theorizes the jury as a site of 'rational disorganization'; it rubs against the grain of a system otherwise driven by the values of expertise and rationalization. It is democracy always already in action, '... a liminal space where lay-citizens get to make official decisions while remaining outside of officialdom' (p. 57). The horizontal exercise of deliberative faculties in making decisions that bear heavily on those subject to the outcome constitutes a powerful fount of democratizing sensibilities. Juries do not simply offer legitimacy to the justice system by bearing witness to its majesty from the inside out; they offer legitimacy through the fact of and the process of their own participation.

Dzur is persuasive as he argues that although voters and politicians as their representatives have brought us an irrational and bloated penal system, experts and professionals 
are not a panacea. Furthermore, the dearth of jury trials, which follows upon a surfeit of plea bargains and power on the part of prosecutorial forces, has most certainly contributed to the surplus of punishment. Without juries, the criminal justice system shuts down on itself; it is rendered unaccountable to those it is supposed to serve.

However, in the current environment, it is fair to ask whether more jury trials would indeed lead to a fairer system of adjudicating harm. Juries watch, listen and deliberate. Unlike in the pre-revolutionary colonial systems, juries in the United States are constituted as triers of fact, not of law. A better image than the Trojan Horse might be that juries are one piece in a complex puzzle of power relationships that constitutes the criminal justice system. The difference the jury makes is clear, and I have no quarrel with Dzur's thinking about the potential for horizontal deliberative practices to create a system of justice seeking more attuned to suffering. His examples of restorative justice programs remind us that if given alternatives to the rationalist dictates of the criminal law, citizens might reach very different conclusions about outcomes. But a restorative justice circle is precisely not a jury. The difference in how they are constituted and placed in the context of justiceseeking systems is crucial to understanding the potential for different outcomes.

In the end, I am not fully persuaded that juries as such are sites where sensibilities about what it means to be guilty of criminal behavior and to deserve certain kinds of punishment will be fundamentally altered. The decline of the jury certainly diminishes the legitimacy of our justice-seeking processes. However, that decline coincides with mass incarceration; it is not before or causative of the phenomenon. The rush to punish on the part of policymakers has created a crisis in the system that results in fewer cases going to trial. But identifying the jury as the participatory mechanism that will ameliorate mass incarceration may be putting the cart before the horse. Dzur offers an original and important rejoinder to democratic theorists to include the jury in our thinking about the punitive powers of the state. However, his reliance on the jury as the site of disruption of a criminal justice system otherwise partial to standardization and efficiency of outcomes may be overly optimistic. It does not adequately take into account the constraints on juries within the context of the larger system.

\section{References}

Barker, V. (2009) The Politics of Imprisonment: How the Democratic Process Shapes the Way America Punishes Offenders. Oxford: Oxford University Press.

Whitman, J. (2003) Harsh Justice: Criminal Punishment and the Widening Divide between American and Europe. Oxford: Oxford University Press. 